\title{
What is the incidence of holoprosencephaly?
}

\author{
E S SAUNDERS, D SHORTLAND, AND P M DUNN
}

From the Department of Neonatal Paediatrics, Southmead Hospital, Bristol BS10 5 NB.

SUMMARY The incidence of holoprosencephaly with normal chromosomes has been estimated at between 1 in 16000 and 1 in 53394 live births. It has been found that during a 3-year period in the Bristol and Weston Health District there were six cases of holoprosencephaly, two of which were familial, and these cases are described. This represents an incidence of 1 in 5200 and during the preceding 3-year period the incidence in the same area was 1 in 14520 births.

Holoprosencephaly was first reported in 1882 by Kundrat $^{1}$ under the term arhinencephaly. He described a spectrum of anomalies characterised by median dysplasia of the face and aplasia of the olfactory bulbs and tracts, hence the term arhinencephaly. Since then, there have been several reports of similar cases, ${ }^{23}$ mostly sporadic but some familial, ${ }^{4-10}$ of which a small number were associated with endocrine dysgenesis. ${ }^{11} 12$

In early reports of holoprosencephaly, chromosome studies were not available, but when this technique became routinely performed it appeared that patients with this anomaly could be divided into two groups: firstly, those with multiple extracephalic malformations who had chromosome abnormalities especially of the 13 to 15 group and, secondly, those with trivial extracranial malformations who had normal chromosomes. Exceptions to this concept do occur and in a review of published reports in 1976 Ming et al ${ }^{13}$ described 21 cases of holoprosencephaly of which 10 had a normal karyotype and 11 had various chromosome anomalies, of which the 13 to 15 group was most common. These 11 invariably had multiple extracephalic abnormalities. It is now accepted that approximately half the cases of holoprosencephaly have normal chromosomes and half are associated with chromosome abnormalities.

The basic pathological malformation in holoprosencephaly is failure of the embryonic prosencephalon to develop into two normal cerebral hemispheres. The term holoprosencephaly is used to cover a graded series of malformations from the most severe with cyclopia, proboscis-like nose, median cleft lip and palate, and single ventricle, through orbital hypotelorism with flat nose and normal lip and palate (usually with a single cerebral hemisphere), to the least affected end of the spectrum

Received for publication 14 June 1983.

Accepted for publication 3 August 1983. with a normal face but absent olfactory bulb and tracts.

The degree of facial malformation usually parallels that of the brain, so that those with the most severe facial malformations have correspondingly severe brain malformations and this correlation has been described by DeMyer et al. ${ }^{14}$ It follows that although most patients with holoprosencephaly have severe malformations which are not compatible with life, those with minor anomalies do survive but with a variable degree of handicap.

\section{Methods}

During the 3-year period from 1 July 1979 to 30 June 1982, six cases of holoprosencephaly have occurred in the Bristol and Weston Health District (formerly the Avon Area Health Authority) and are described later. The six cases were identified by going through the records from the two special care baby units in the area, to which all the babies with this anomaly would have been admitted. No case was known to have been born outside these two maternity hospitals.

All the cases were diagnosed in the neonatal period and all had normal chromosomes apart from one where there was an abnormality of the $\mathrm{X}$ chromosome (see case 4). Four of these infants had necropsies which confirmed the diagnosis of holoprosencephaly, and in the remaining two necropsy was refused, but the facial appearances were considered characteristic of the anomaly.

Minimal diagnostic criteria are considered to be orbital hypotelorism with variable features of incomplete midline development, such as cleft lip and palate and absence of the philtrum or nasal septum. Absent olfactory bulb and tracts have been described as pathognomonic of the condition, ${ }^{14}$ but this abnormality is usually only confirmed at necropsy. During the same period there were two 
patients with facial features of holoprosencephaly who had trisomy 13.

To obtain the incidence of holoprosencephaly the total number of live and stillbirths was ascertained from figures from the Avon Area Health Authority. To investigate if there were any cases of holoprosencephaly among the stillbirths, we studied the stillbirth registers but none had abnormalities suggestive of this diagnosis apart from case 3 . Ninety-three percent of babies stillborn and those who die in the neonatal period in the Bristol and Weston Health District have necropsy examinations and all necropsy reports during this time were studied.

A similar procedure was undertaken from 1 July 1976 to 30 June 1979 to obtain the incidence during the preceding 3 years.

\section{Case reports}

CASE 1

This female infant was born to a 19-year-old married primigravida and a 36-year-old father. The pregnancy was complicated by low urinary oestriols. Labour started spontaneously at 41 weeks and delivery was normal with Apgar scores of 1 and 5 at 1 and 5 minutes. The baby required intubation and ventilation for 4 minutes.

Birth weight was $2 \cdot 290 \mathrm{~kg}$ and on examination there was bilateral microphthalmos, hypotelorism, and bilateral unstable hips. At 2 hours the baby became cyanosed and started convulsing. The neonatal period was complicated by temperature instability, poor feeding, thrombocytopenia (for which antiplatelet antibodies were found in maternal blood), and continued convulsions. An electroencephalogram on the 11th day was abnormal, suggesting a structural lesion.

The baby's condition deteriorated and she died on the 26th day. Necropsy showed an absent left optic nerve, absent olfactory nerves, and a common cerebral ventricle consistent with holoprosencephaly.

CASE 2

This male infant was born to a 24 -year-old married primigravida and a 27 -year-old father. The pregnancy was normal and there was spontaneous onset of labour at 42 weeks. Delivery was normal, with Apgar scores of 7 and 9 at 1 and 5 minutes, and his birth weight was $3.390 \mathrm{~kg}$.

On examination there was microsephaly, a midline cleft lip and palate, hypotelorism, and depressed nasal bridge. The baby had generalised convulsions from the age of 2 days. A CT scan was performed on the 10th day and showed grossly dilated lateral ventricles with thin cerebral cortex consistent with hydranencephaly (figs 1 and 2). The baby died on the 26th day.

Necropsy showed a single cerebral hemisphere with closely approximated orbits and absent olfactory nerves. The mother has subsequently given birth to a normal girl and boy.

\section{CASE 3}

This was a stillborn male infant born to a 25 -year-old married primigravida and 30-year-old father. Pregnancy was complicated by vaginal bleeding at 11 weeks, and at 37 weeks labour was induced because of hypertension, hydramnios, and breech presentation.

At delivery, hydrocephalus was present which required draining to allow birth of the head. At is necropsy the birth weight was $2 \cdot 510 \mathrm{~kg}$. The facial features are shown in fig 3 and included a single eye and proboscis-like nose. There was also a small exomphalos and polydactyly. The brain showed a

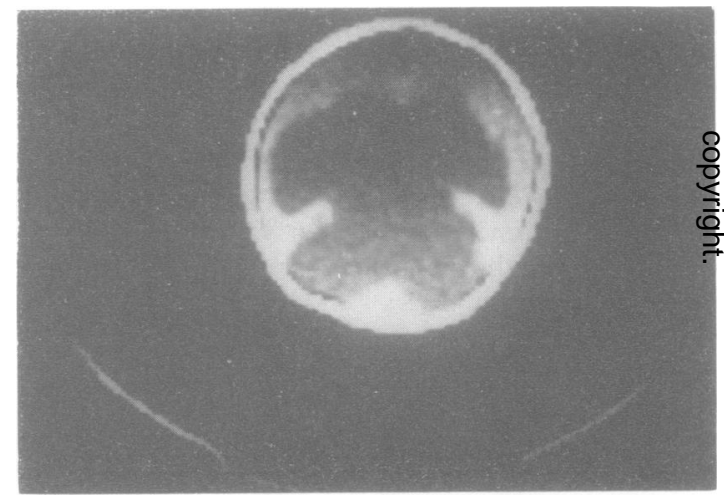

FIG 1 CT scan of case 2 showing single ventricle.

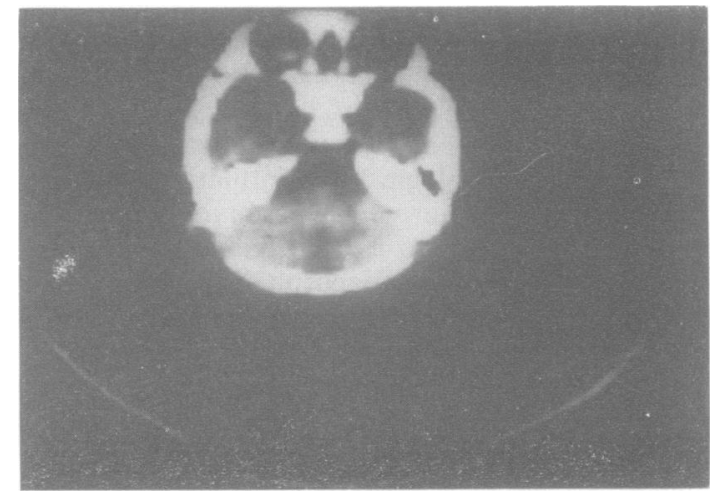

FIG 2 CT scan of case 2 at the level of the sphenoid bones. 


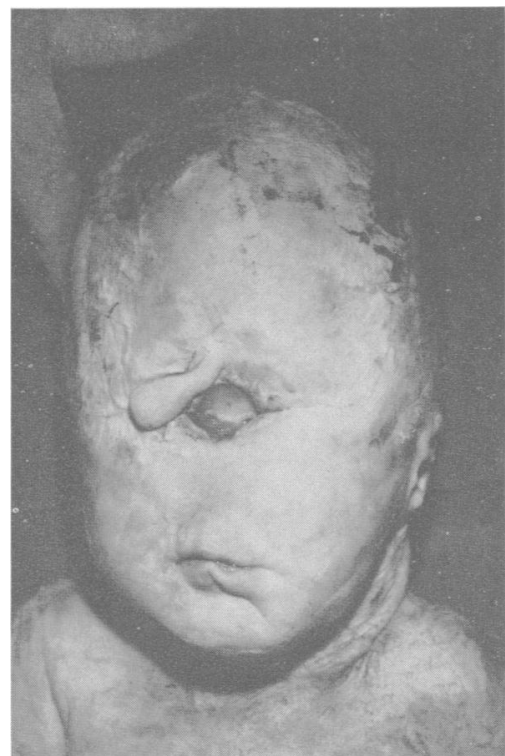

FIG 3 Facial features of case 3 showing a single eye and proboscis-like nose.

single ventricle, absent olfactory nerves, and a single optic nerve. No chromosome studies were performed. Fifteen months later the mother gave birth to a normal female infant.

\section{CASE 4}

The mother of this case was 26 years old and had delivered a normal boy 2 years before. Her labour started spontaneously at 39 weeks and she had a normal delivery of a female infant. Apgar scores were 8 and 10 , and birth weight was $2.44 \mathrm{~kg}$. Examination showed microcephaly, with a skull circumference of $27 \mathrm{~cm}$, hypotelorism, and a central cleft lip and palate. There was a small nose with a single nostril. The facial features are shown in fig 4 . The baby was also noted to have short limbs.

A CT scan on the 15th day showed a single ventricle and a narrow rim of cerebral cortex, as shown in fig 5. Chromosome studies showed a mosaic of a normal cell line and a line with an absent short arm of one X chromosome:karyotype $46, X X / 46, X$, $\operatorname{del}(\mathrm{X})(\mathrm{p} 11)$. Chromosome deletions of this type are usually associated with Turner's syndrome but when the baby died at 38 days necropsy was refused and so the ovaries were not examined. Both parents had normal karyotypes.

\section{CASE 5}

The mother of this baby was 29 years old, married, and Rhesus negative. Nine years previously she had had a termination of pregnancy and anti-D was not given. One year previously she had had a spontaneous abortion at 11 weeks' gestation and Rhesus antibodies were present.

Labour was induced at term by dates (though only 36 weeks by clinical assessment) because of low oestriols and rising anti-D titres. Apgar scores were 7 and 9 , birth weight was $1.68 \mathrm{~kg}$, and estimated gestation was 'term'. There was a small anterior fontanelle, a small rudimentary nose, and a central cleft lip, but the palate was intact apart from a small notch anteriorly. There was hypotelorism with a

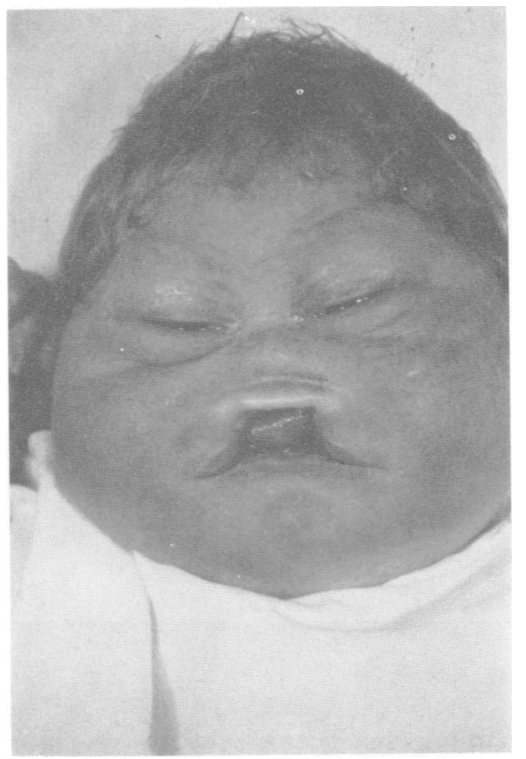

FIG 4 Facial features of case 4 showing microcephaly and a central cleft lip.

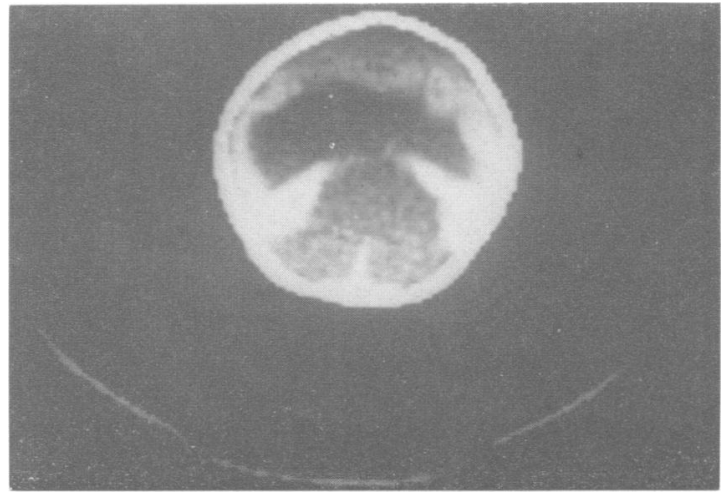

FIG $5 C T$ scan of case 4 showing a single ventricle. 
right microphthalmos and coloboma. There was a left sided chest depression, sacral agenesis, and bilateral positional talipes calcaneovalgus. These features are shown in figs 6,7 , and 8.

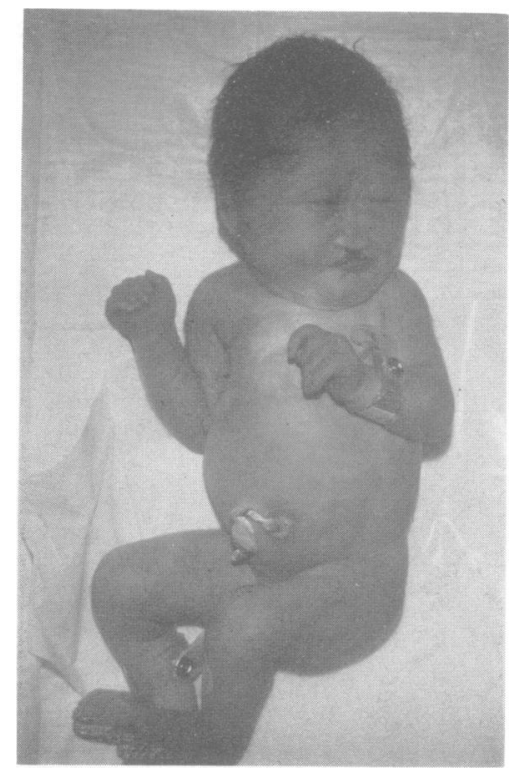

FIG 6 General appearance of case 5.

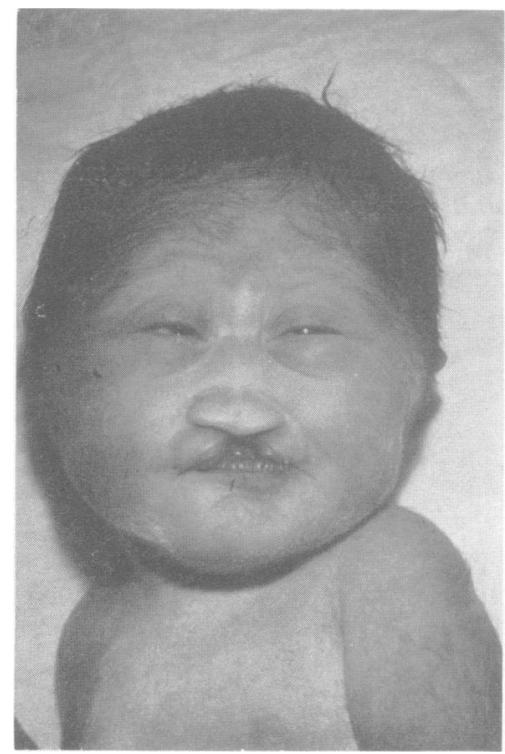

FIG 7 Facial features of case 5 showing hypotelorism and cleft lip.

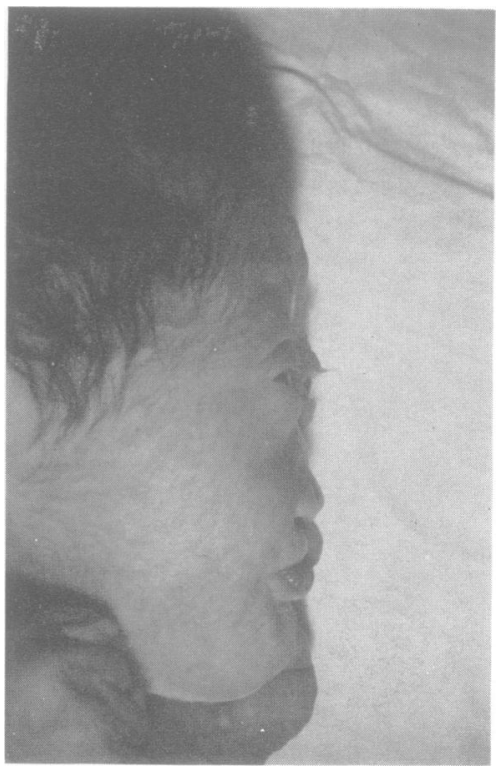

FIG 8 Lateral view of face of case 5 showing flattened features.

The Coombs test was strongly positive and th baby was Rhesus positive, but there was no proble with hyperbilirubinaemia or anaemia. The baby's o condition slowly deteriorated and she died at 8 days. Necropsy was refused but the features were consis- $\stackrel{\mathbb{Q}}{2}$ tent with holoprosencephaly.

CASE 6

This case is the sister of case 5 and was born one year later. Elective Caesarean section was performed at 36 weeks because of Rhesus antibodies. Apgar score was 2 at 1 minute but because of gross midline facial abnormalities intensive resuscitation was not performed. Birth weight was $1.82 \mathrm{~kg}$ and there was $ᄋ$ hypotelorism, bilateral microphthalmos, a single tubular nostril, midline cleft lip and palate, and 음 bilateral dislocatable hips. The facial features are $\rightarrow$ shown in fig 9. Necropsy showed a large single ventricle and absence of cranial nerves I, II, VI, N and VIII.

During a subsequent pregnancy this mother had $\mathbb{O}$ two ultrasound scans at King's College Hospital at 17 and 22 weeks by dates. These both showed $\widetilde{\sigma}$ bilateral cerebral ventricles which appeared normal 0 and there was no evidence of facial clefting. We are $\overparen{D}$ happy to report that she had a normal delivery at $\stackrel{?}{+}$ term of a healthy female infant with a birth weight 0 of $3.060 \mathrm{~kg}$. Ultrasound scan of the brain at the age of 1 hour was normal. 


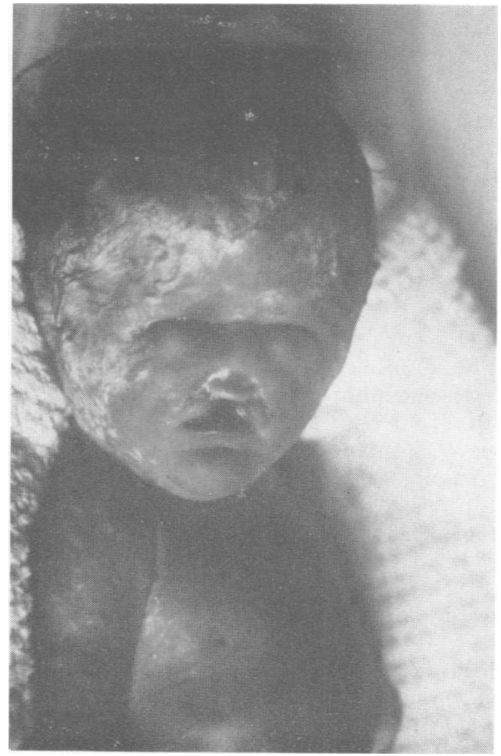

FIG 9 Facial features of case 6 showing hypotelorism, bilateral microphthalmos, and cleft lip.

\section{Results}

During the 3-year period from 1 July 1979 to 30 June 1982 , there were six cases of holoprosencephaly as described, and the total number of births in the Bristol and Weston Health District was 31225 . The incidence of holoprosencephaly was therefore 1 in 5200.

\section{Discussion}

The incidence of holoprosencephaly with a normal karyotype has been reported at between 1 in $16000^{15}$ and 1 in $53395^{16}$ births. During the past 3 years in the Avon district we found the incidence of holoprosencephaly to be 1 in 5200 and this is much higher than previously reported. The incidence for the preceding 3 years of 1 in 14520 was, however, comparable with some previous estimates.

Although the number of cases is small, applying the Poisson distribution, the increase in incidence from that reported at 1 in 16000 to our incidence of 1 in 5200 is statistically significant $(p<0.05)$. The increase in incidence which occurred during the two consecutive 3 -year periods studied is also statistically significant. Further studies will be needed to see if this incidence varies.

Holoprosencephaly has been produced by a variety of teratogenic agents in animals and occurs in lambs if the pregnant ewe ingests the plant Veratrum californicum. ${ }^{17}$ However, no known teratogenic agent has been identified in humans. Among our cases, the average maternal age at delivery was 25 years and the average paternal age 30.5 years. All the parents were unrelated and without malformations. In particular, they carried no stigmata of mild forms of holoprosencephaly, such as absent smell, hypotelorism, or cleft lip and palate. There was no significant family history, although the mother of cases 5 and 6 had a brother who suffered from epilepsy and died at 18 years.

All the fathers were in social class III or IV by the Registrar General's classification except for one father who was unemployed. The only drugs taken by the mothers during pregnancy, apart from iron and vitamins, was dimotane taken by the mother of cases 5 and 6 during the second month of the pregnancy resulting in case 5 . There were no reported viral infections during the pregnancies and, apart from a threatened abortion at 11 weeks in case 3 , there were no first trimester pregnancy complications. Hydramnios was only present in case 3 . No recognisable environmental factor has been identified to account for this high incidence.

Our six cases exhibited the various degrees of holoprosencephaly from the most severe (case 3 ) with cyclops, a proboscis-like nose, and gross hydrocephalus to the less severe with hypotelorism and microphthalmos but normal lip and palate (case 1). The more usual cleft lip and palate were demonstrated by the remaining cases.

It is interesting that in case 4 the karyotype showed a variation of one $X$ chromosome usually found in Turner's syndrome. Although the baby's length was normal $(50 \mathrm{~cm})$, the limbs were noted to be short, and it is possible this baby had Turner's syndrome in addition to holoprosencephaly. An abnormality of the X chromosome with holoprosencephaly has not previously been described. Unfortunately this association could not be proved as no necropsy was performed.

Although most cases of holoprosencephaly are sporadic, there have been several reported cases of familial holoprosencephaly with normal chromosomes, ${ }^{4-10}$ and our cases 5 and 6 belong in this category. There have been more female than male cases reported and, as a result, an X linked mode of inheritance has been proposed..$^{15}$ It has also been postulated that the familial cases are the result of a single gene defect with variable expressivity which is transmitted as an autosomal recessive trait. ${ }^{18}$ The recurrence rate would therefore be 1 in 4 and this is consistent with previous familial cases. The sporadic 
type has a minimal risk of recurrence and this is important for genetic counselling.

As yet there is no known method of determining to which group the parents of an affected baby belong. For the future, however, as ultrasound techniques improve, affected fetuses could be recognised and termination of pregnancy offered. If the ultrasound examination is not conclusive, fetoscopy could be performed, bearing in mind the procedure is not without risk.

We thank Dr B D Speidel for permission to report his cases, Mr A Hughes for statistical advice, and Miss J A Hughes for secretarial assistance.

\section{References}

1 Kundrat H. Arhinencephalie als Typsche Art Von Missbildung. Graz: Leuschner and Lubensky, 1882.

2 Landau JW, Barry JM, Koch R. Arhinencephaly. $J$ Pediatr 1963;62:895.

3 Bishop K, Connolly JM, Carter CH, Carpenter DG. Holoprosencephaly. J Pediatr 1964 ;65:406-14.

4 DeMyer W, Zeman W, Palmer CG. Familial alobar holoprosencephaly (arhinencephaly) with median cleft lip and palate. Report of patient with 46 chromosomes. Neurology (Minneap) 1963;13:913-8.

5 Khan M, Razdilsky B, Gerrard JW. Familial holoprosencephaly. Dev Med Child Neurol 1970;12:71-6.

6 Godeano D, Winter ST, Dar H. Familial holoprosencephaly with median cleft lip. J Genet Hum 1973;21 :223-8.

7 James E, Van Leeuwen G. Familial cebocephaly. Case description and survey of the anomaly. Clin Pediatr 1970;9:491-3.
8 Holmes LB, Driscoll S, Atkins L. Genetic heterogenicity of cebocephaly. J Med Genet $1974 ; 11: 35-40$.

9 Dellaire L, Fraser C, Wiglesworth FW. Familial holoprosencephaly. Birth Defects 1971 ; 7:136-42.

10 Dominok GW, Kirchmair H. Familial incidence of malformations of arhinencephalia group. $Z$ Kinderheilkd $1961 ; 85: 19-30$.

11 Hintz RL, Menking M, Sotos JF. Familial holoprosencephaly with endocrine dysgenesis. $J$ Pediatr $1968 ; 72$ : 81-7.

12 Begleiter ML, Harris DJ. Holoprosencephaly and endocrine dysgenesis in brothers. Am J Hum Genet $1980 ; 7: 315-8$.

13 Ming PM, Goodner DM, Park TS. Cytogenetic variants in holoprosencephaly. Report of a case and review of the literature. Am J Dis Child 1976;130:864-7.

14 DeMyer W, Zeman W, Palmer CG. The face predicts the brain: diagnostic significance of median facial anomalies for holoprosencephaly (arhinencephaly). Pediatrics 1964; 34:256-63.

15 Roach E. DeMyer W, Conneally PM, Palmer C, Merritt AD. Holoprosencephaly: birth data, genetics and demographic analyses of 30 families. Birth Defects 1975; XI(2):294-313.

16 Myrianthopoulos NC, Chung CS. Congenital malformations in singletons: epidemiologic survey. Birth Defects $1974 ; \mathbf{X}(11): 1-58$.

17 Binns W, James LF, Skupe JL, Thacker EJ. Cyclopian type malformations in lambs. Arch Environ Health $1962 ; 5: 106$.

18 McKusick VA. Holoprosencephaly, familial alobar (arhinencephaly). In: Mendelian inheritance in man. 4th ed. Baltimore: Johns Hopkins University Press, 1975:448-9

Correspondence and requests for reprints to Dr E 尺्रें Saunders, Special Care Baby Unit, Southmead? Hospital, Westbury-on-Trym, Bristol BS10 5NB. 